\title{
A contribuição do pensamento de José Ortega y Gasset sobre o tema da vida na filosofia contemporânea
}

The contribution of Jose Ortega y Gasset's thinking on life in the contemporary philosophy

\section{RESUMO}

O presente artigo desenvolve a contribuição do pensamento de José Ortega y Gasset, filósofo espanhol que dedicou parte da sua obra a pensar questões relacionadas à vida humana e a propor um método filosófico denominado raciovitalismo. $\mathrm{O}$ conceito de vida em Ortega é fundamental para adentrarmos a qualquer reflexão proposta pelo filósofo ao considerá-lo como categoria chave no processo de compreensão da realidade. Do vitalismo de Nietzsche ao historicismo de Dilthey, Ortega considera apresentar com originalidade o seu pensamento vital ao propor uma reflexão que concebe a vida como acontecimento, e essa, como sendo uma realidade pessoal. Para tanto, compreender essa realidade considerada por ele como radical, implica em se apropriar da razão como órgão de compreensão que não está restrito somente ao processo de teorização científica ou filosófica. A razão vital como método auxilia o indivíduo a compreender-se dentro da sua história de vida que é marcada por inúmeras contradições.

Palavras-chave: Vida humana. Razão vital. História de vida.

\section{ABSTRACT}

This article unfolds the contribution of Jose Ortega y Gasset's thinking, a Spanish philosopher who dedicated part of his work to think on issues related to human life and to propose a philosophical method called vital reason. Ortega's concept of life is fundamental to engage in any reflective thinking proposed by the philosopher considering it as a key category in the process of understanding reality. From

* Doutor em Filosofia (UFMA). https://orcid.org/0000-0002-61 16-9550 
Nietzsche's vitalism to Dilthey's historicism, Ortega considers presenting his vital thought with originality by proposing a reflection that conceives life as an event, and this, as a personal reality. Accordingly, to understand this reality considered by him as radical implies to seize reason as an organ of understanding that is not restricted only to the process of scientific or philosophical theorization. The vital reason as a method helps the individual to understand himself within his life history, which is marked by innumerable contradictions.

Keywords: Human life. Vital reason. History of life.

O pensamento de Ortega aparece no cenário filosófico europeu do século XX como uma via de superação da dicotomia vida e razão e com o objetivo de construir uma reflexão sobre as questões concretas em torno da cultura espanhola a partir da realidade social e política da Espanha. Desde a publicação de Meditaciones del Quijote (1914), Ortega apresentou interesse intelectual e político pelas questões históricas e culturais da Espanha, propondo, assim como outros intelectuais, uma mudança na vida cultural do país espelhada nas ideias iluministas e liberais da Europa do século XX. Refletir sobre a possibilidade de um novo país será uma das maneiras encontradas por ele de orientar-se na vida.

Em Meditaciones del Quijote (1914), Ortega inicia esclarecendo ao leitor que todos os temas apresentados na obra versam direta ou indiretamente sobre a Espanha (Cf. ORTEGA Y GASSET, 2010, p. 43-44). Esse livro tem como pano de fundo a preocupação da geração de Ortega, cuja questão central era a definição do que era a Espanha. De Meditaciones de Quijote (1914) a España Invertebrada (1921), o que se vê nas análises dos textos políticos de Ortega é o reconhecimento da grave enfermidade que assolava a vida social dos espanhóis. E foram os problemas reconhecidos no contato com a sua realidade que fizeram de Ortega um pensador preocupado com a vida nacional e consciente do seu papel de influenciador de opiniões por meio do seu ofício intelectual.

A filosofia de Ortega germina nesse contexto social, com toda sua profundidade reflexiva e, ao mesmo tempo, extremamente pragmática, no sentido de que aparece como uma forma de possibilitar à Espanha o fazer Filosofia, ao discutir seriamente as questões debatidas no cenário da Filosofia europeia. Com Ortega, a Espanha ganha representatividade no cenário filosófico contemporâneo e, diferentemente do que poderia ocorrer, ele vai às fontes do que tinha de mais atual naquele momento: a Filosofia alemã. Porém, mesmo sofrendo fortes influências de Kant, Husserl, Nietzsche e Dilthey, Ortega não se apresenta como representante de nenhuma corrente filosófica já existente. Em busca de uma originalidade de pensamento, desenvolve ao longo de sua trajetória intelectual uma proposta de pensamento que vai ser definida como razão vital e histórica.

Além da preocupação circunstancial prática, no campo estritamente teórico, o pensamento filosófico de Ortega busca encontrar um fundamento que supere a ontologia tradicional, especificamente o que aparece em Heidegger. Segundo Gracia (2014), retomando a interpretação de José Gaos (1957), há em Ortega uma antipatia congênita pela ontologia. Contudo, será pela ontologia de Heidegger que Ortega percebe o significado da sua ontologia, ao buscar contrapor-se à teoria 
do ser pela sua filosofia do sendo. Ao Ser e Tempo (1927), Ortega reclama o reconhecimento de ter antecedido Heidegger em algumas ideias, que já teriam sido desenvolvidas por ele em 1914 ao apresentar o conceito de homem circunstanciado na publicação de Meditaciones del Quijote (1914).

Enquanto Heidegger busca fundamentar uma metafísica via existência, Ortega preocupa-se em pensar a vida mesma em seu desenvolvimento histórico. Segundo Bonilla (2002, p.375), a propagação de Heidegger ter descoberto a ideia de vida e de existência enojava Ortega por dois motivos que aparecem na nota de seu artigo "Pidiendo un Goethe desde dentro" (1932): o entendimento de que havia antecipado esses temas e o sentimento de que não tinha sido compreendido. Nessa nota, além de criticar Heidegger, ele critica a possibilidade de o filósofo alemão ter superado o substancialismo. Ortega considera que a ideia de Dasein era um caminho acertado para superar a crise intelectual do Ocidente.

$\mathrm{Na}$ leitura de Gracia (2014), Ortega faz a crítica de que o tempo da ontologia já terminara com os gregos e que não poderia, com autenticidade, voltar a passar a ninguém; por isso, foi uma frivolidade, um capricho acadêmico de Heidegger, querer ressuscitá-la, com o que teria conseguido somente fazer-se ele mesmo uma bagunça. Porém, mesmo que Ortega seja um crítico convicto de Heidegger, para alguns estudiosos como Bonilla, o pensamento heideggeriano foi fundamental para Ortega objetivar o seu pensamento através de uma maior clareza e sistematização do seu pensamento filosófico.

A hegemonia do pensamento de Heidegger desde os finais de 1927 interfere na postura filosófica de Ortega, que inicia uma disputa intelectual para firmar sua originalidade filosófica frente às teorias que, de alguma forma, ameaçavam a sua construção intelectual, marcando desde então uma linguagem filosófica do ser como construção teórica do sujeito vivente e relacional. Para reforçar o sentimento de competição, os seus melhores discípulos encontravam-se fascinados por Heidegger: de Zubiri a Gaos. Através de suas publicações e cursos, principalmente a partir de 1929, nota-se uma intensa campanha para propagar o que já parece ser sua filosofia.

O conteúdo constitutivo da realidade que toca todas as demais é marcado por uma dimensão ontológica dinâmica que escapa a qualquer aspecto de uma realidade fixa e determinada. O que Ortega desenvolve ao longo do seu pensamento é a concepção de uma realidade que se compreende através de manifestações distintas do papel da razão enquanto faculdade humana que organiza e capta a compreensão do sentido das coisas ao aparecer na vida concreta do indivíduo através da constatação da vida como realidade radical ${ }^{1}$. A constatação é de que não há uma realidade na vida humana que esteja separada do sujeito vivente, pois todas as demais realidades só ganham sentido na relação com a vida humana. É a partir dessa concepção de vida que Ortega desenvolve sua proposta filosófica do raciovitalismo.

Diagnosticada por Ortega em sua obra História como um sistema (1935), a sociedade moderna caracteriza-se pela crença excessiva na razão físico-matemática que faz uso de métodos objetivos para esclarecer os fenômenos da natureza, mas que, no campo dos assuntos humanos, apresenta-se frágil por fazer uso de

${ }^{1}$ A partir de Qué es filosofía? (1929), a filosofia orteguiana segue com o conceito fundamental da vida humana - a vida como realidade radical pela qual se deve compreender todas as demais (Cf. LASAGA, 2015, p.37). 
categorias oriundas de uma realidade natural. Aras (2008, p. 196) entende que há dois momentos de Ortega frente à razão: um negativo e outro positivo. $O$ primeiro revela a postura crítica de Ortega, certamente ainda com forte influência de suas leituras da crítica de Nietzsche à razão moderna; e o segundo é construtivo, ao conseguir estruturar uma proposta metodológica de razão capaz de dar conta da vida humana, inicialmente via razão vital e, em seguida, com clareza e maturidade de seu caminho filosófico, com a definição da razão histórica e narrativa.

No entender de Medina (2003), o momento que caracteriza o primeiro Ortega propunha uma filosofia centrada na diferença entre vida e cultura, pensada com base na categoria central do sujeito, pensado à maneira kantiana. Compreende-se o homem como cosmopolita capaz de produzir cultura e de realizar formas ideais válidas para toda a humanidade. Entretanto, Ortega supera essa visão idealista ao reconhecer que tal proposta de inspiração kantiana se torna inviável por se fundamentar em um modelo de razão pura, isenta de qualquer influência sensível. Ortega acredita que a superação dessa forma de pensar acontece pela integração entre homem e circunstância, preconcebendo o sujeito constituído em uma relação circunstancial. Integra-se a essa dialética o perspectivismo oriundo de um pensamento circunstanciado pelo qual o indivíduo e a circunstância são elementos constitutivos e indissociáveis da realidade radical, que no entender do filósofo é a vida mesma enquanto acontecimento pessoal e intrasferível.

A crise da razão moderna está diretamente relacionada, para Ortega, aos limites que essa mesma razão encontra ao ter que lidar principalmente com os assuntos humanos que seguem uma lógica de compreensão distinta dos objetos da natureza. A questão Orteguiana em relação à razão não é quanto à sua função teorética, visto que, para ele, esse tipo de conhecimento só se alcança de fato por ela; a sua crítica é direcionada a um movimento que absolutiza o poder da razão na compreensão de todas as realidades por meio de sua função objetiva, o racionalismo. Para Marías (1948, p. 48-49), "la razón vital no es una forma particular de la razón, sino que es la razón sin más, en su sentido pleno e eminente". Para Ortega, o verdadeiro sentido da palavra razão consiste em toda ação intelectual que insere o homem em contato com a sua realidade (CONILL-SANCHO, 2012, p. 182), sendo que "en cualquier caso, la razón es averiguación, indagación y descubrimiento." (SEVILLA, 2001, p. 141).

Frente a essa constatação, a postura de Ortega é de conciliação entre vida e razão, fazendo dela uma "forma ou função da vida". Aras (2008) retoma alguns nomes que, ao fazerem a crítica, caíram no irracionalismo como foi o caso de Unamuno sob influência de Kierkegaard, mas o que Ortega faz tempranamente é buscar um ponto de ligação que possibilitasse compreender a vida na sua dimensão relacional, desde quando em Meditaciones del Quijote (1914) já afirmava que o homem é com sua circunstância.

Para Ortega, o grande problema da modernidade a partir de Descartes foi construir uma teoria da racionalidade separada da vida. Descartes, já em sua referência ao sujeito, se apropria do termo res que está sempre acompanhado de uma carga semântica das ciências da natureza pelo fato de significar uma coisa, algo que requer uma objetividade estática. $O$ erro foi partir da ontologia dos gregos, sendo que, para sua superação, se faz necessário ir além das noções tradicionais 
de ser, de res e de natureza. O erro do naturalismo consiste em tratar as realidades como se fossem ideias, conceitos, identidades.

O mundo da vida parece ser desqualificável frente ao mundo geométrico ao conceber uma razão superior a toda as demais realidades e capaz de desvendá-las através de seus variados métodos. As ciências do espírito não foram capazes de construir uma crença nessa mesma razão que por séculos conseguiu estruturar conhecimentos seguros no campo da natureza. A razão moderna se afirma demasiadamente pura pela exatidão matemática e seu rigor sublime para dar conta desse espetáculo que é a vida humana, circunstanciada e indeterminada historicamente.

Ortega acusa as ciências do espírito de buscarem compreender o humano dentro desse modelo de razão, acreditando na possibilidade de apreendê-lo em conceitos objetivos, assim como faz Kant ao propor uma razão prática pura. $\mathrm{Na}$ obra Metafísica dos costumes, Kant entende que a vontade (pura) é capaz de legislar por uma razão pura ausente da experiência, capaz de garantir um princípio de universalidade, chegando a afirmar que a metafísica dos costumes é propriamente a moral pura, na qual nenhuma antropologia (nenhuma condição empírica de caráter fisiológico ou pragmático) é colocada como fundamento, e que "a Filosofia moral fundada inteiramente na sua parte pura, aplicada ao homem, fornece-lhe como ser racional leis a priori." (KANT, 1999, p. 16). O problema anunciado por Ortega é que, de Descartes a Kant, a Filosofia pensa a realidade a partir da teoria do conhecimento.

Para Ortega, a Filosofia grega e medieval, diferente da Filosofia moderna, foi uma ciência do ser e não do conhecer. A pergunta passa do que posso conhecer para como posso conhecer. A verdade é posta em questão. Seguindo os neokantianos, Ortega atribui a Kant intenções de uma fundamentação epistemológica das ciências, distanciando-o do interesse em problematizar a metafisica.

No entanto, a vida humana enquanto realidade radical que acontece em primeira pessoa carece ser pensada dentro dos limites e ditames de sua historicidade. Entende-se, assim, que o homem não tem natureza, mas história ${ }^{2}$, e esta, é um quehacer constante em meio ao exercício da liberdade. Em 1914, Ortega já faz referência ao yo como não sendo uma coisa, mas como um conjunto de ações que o homem executa, ou seja, compreende-se o eu como executivo. Essa ideia vai ganhando força e configura o conceito de quehacer, categoria central na concepção orteguiana de vida humana.

Em Meditación de la técnica (1965), Ortega vai inserir o conceito de natureza como um conjunto de facilidades ou dificuldades que o homem enfrenta para viver, não sendo ele nem seu corpo nem sua alma, mas um drama, por não ter realidade, mas um programa, uma aspiração de ser em um esforço contínuo de autofabricar-se. Com o conceito de produção, Ortega se distancia de qualquer perspectiva idealista da vida. Ele afirma categoricamente que a vida para o homem não é teoria, mas antes fabricação de si mesma que começa com a técnica. No Ensaio de Estética (ORTEGA Y GASSET, 2017), aparece essa compreensão do eu como executivo enquanto o sujeito. A expressão na literatura orteguiana caracte-

\footnotetext{
${ }^{3}$ A dimensão histórica da vida que aparece no pensamento de Ortega sofre influência do pensamento historicista de Dilthey, que considera a vida como primeira categoria do mundo histórico, ao qual Ortega vai chamar de realidade radical pelo fato de todas as demais aparecerem a partir do fenômeno da vida.
} 
riza a vida como ontologicamente incompleta, trazendo a figura do herói para anunciar a luta que o homem trava para fazer sua própria vida, que, por ser em circunstância, aparece sempre como algo a ser feito, indefinido.

O herói Orteguiano que aparece nas Meditaciones del Quijote (1914) denota o herói que habita em cada indivíduo, porque, analogamente, cada pessoa é seu pequeno cavaleiro, ou seu modesto cidadão; fazer da sua realidade uma realidade mais cheia de si mesmo é encher de sentido o próprio eu, porém o eu somente se chama a si mesmo completando o que germina em seu entorno, entendendo-o, dotando-o de sentido, e essa é a chave de compreensão antropológica de Ortega. Ortega lê a novela realista do século XIX como um desmoronamento banal das ilusões do herói, porque o herói aspira pouca coisa. O herói é aquele que busca ser ele mesmo ante sua circunstância, por isso todos buscam ser esse herói que quer ser, mas que não será nunca, pois ser herói consiste em ser uno, negar-se a repetir os gestos que o costume, a tradição, ou o que os instintos biológicos lhes forçam a fazer. Todos levam esse herói que luta com a conveniência e com a sensatez, o prático e o útil, mas que leva, ao mesmo tempo, escondido em si, o plebeu interior que se burla a si mesmo e carece de prudência, vivendo na fronteira entre o ridículo e o trágico (GRACIA, 2014, p. 3115-3143).

O conceito de razão vital (MARÍAS, 1948, p. 58; 88), desenvolvido por Ortega para pensar a vida humana na sua constituição circunstancial, parece ser razoável ao propor uma compreensão do homem historicamente circunstanciado que não pode ser completamente compreendido por uma razão pura de herança cartesiana. Para Marías, a razão vital põe o homem em contato com a realidade mesma, ou seja, com sua própria vida. Por isso, a forma concreta da razão vital é a razão histórica, pois, por ela, a vida ganha sentido pelas experiências. Nesse sentido, é que parece ser compreensível a definição da razão vital como método feita pelo comentador orteguiano.

A modernidade marca a crença no primado de uma razão positivista que pensa o humano por categorias das ciências naturais. A partir da ideia desenvolvida em Historia como sistema (1935) de que o homem não tem natureza, mas história, essa tentativa de compreensão do humano justifica a descrença contemporânea nas ciências do espírito que não conseguem, com a mesma exatidão das ciências da natureza, clarificar os fenômenos humanos. $O$ fracasso dessa razão herdeira da razão físico-matemática frente aos assuntos humanos é a porta de entrada da reflexão filosófica de Ortega ao reconhecer que tal constatação "deixa o caminho livre para a razão vital e histórica" (ORTEGA Y GASSET, 2008b, p. 35).

O esclarecimento do que vem a ser a vida humana marca o argumento principal no pensamento filosófico orteguiano. A vida humana enquanto acontecimento pessoal e intransferível, no qual todas as demais realidades aparecem, faz com que a vida seja compreendida pelo conteúdo de sua historicidade e não pelos mecanismos naturais que as circunstâncias biológicas marcam na existência humana por uma "absoluta atualização". O fato de a vida humana não possuir uma substância ontológica significa que não existe no homem uma substância capaz de justificar sua vida pessoal, assim a compreensão do humano parece não passar pelo que ele é, mas sim pelo que ele vive. Ortega estrutura uma concepção de vida humana partindo da existência histórica concreta do sujeito vivente que co- 
necta circunstância e perspectiva, ou seja, o aqui e agora com que cada um forçosamente lida no cotidiano da sua vida.

Nicol (1950) integra o grupo de especialistas em Ortega que divide o pensamento raciovitalista em dois períodos: o primeiro, mais biológico; e o segundo, mais historicista. A divisão parece ser um pouco problemática, porque, para alguns especialistas em Ortega, seria um erro acusá-lo de biologista, visto que, se assim fosse, ele compreenderia a vida em sua dimensão histórica natural, reduzindo o homem à vida animal, porém o que Ortega faz desde as Meditaciones del Quijote (1914) é refletir sobre a vida em toda a sua amplitude. O que aparece claramente em sua obra é um certo psicologismo, principalmente em El tema de nuestro tiempo (1923), mas ele logo supera tal perspectiva ao fazer uma revisão de interpretação do conceito de vida nas obras posteriores. A vida deve ser pensada a partir dela mesma e não de uma estrutura ou categoria específica, mas tudo deve ser explicado e compreendido a partir da vida que é temporal, histórica e circunstancial, visto que a vida é uma realidade em processo, que está em constante devir, bem diferente do que concebe o idealismo hegeliano em que a história é uma manifestação ordenada do Espírito absoluto (LASAGA, 2015).

Os primeiros escritos de Ortega sofrem influência do pensamento de Nietzsche e de Bergson e os posteriores, publicados a partir de 1924, aproximam-se, em parte, do historicismo presente nas obras de Dilthey e de Heidegger ${ }^{3}$. A história é um tema recorrente nos escritos de Ortega desde a sua formação acadêmica. Ao doutorar-se em Filosofia, defende a tese intitulada "Los terrores del año mil. Crítica de una leyenda" (1904). Sob influência do pensamento neokantiano, a história estará ligada ao tema da cultura, compreendendo-a como reconstrução orgânica das variações de um sujeito, da cultura ou do conjunto de atividades espirituais características dos homens. Na maturidade do seu pensamento, compreende a história como resposta aos problemas vitais situados circunstancialmente por cada homem e, por essa razão, a cultura deve ser analisada historicamente como parte que integra a vida individual e interindividual e não como verdadeira substância da história (BONILLA, 2013).

Mesmo marcando essa divisão, a vida humana é o tema central de sua obra e perpassa todos os momentos do seu pensamento filosófico. El tema de nuestro tiempo (1923) e Las Atlántidas ${ }^{4}$ (1924) são as duas obras desse primeiro momento vitalista. Na última obra citada, Ortega ensaia adentrar a perspectiva histórica do seu pensamento, avançando na sua concepção de razão histórica nos escritos posteriores - Filosofía de Hegel y la historiología (1928) e Pidiendo un Goethe desde dentro (1932). Contudo, a maturidade de um pensamento mais historicista advém com a publicação de Historia como sistema (1935), obra que traz uma abordagem ontológica da história em relação à vida humana.

Esta última obra é considerada a mais original do pensamento historicista orteguiano por conceber a vida humana como realidade radical que acontece em primeira pessoa em uma ontologia historicizada. Não existe nada além do que o próprio sujeito faz no acontecer de sua vida, sendo que a razão vital não pode

\footnotetext{
${ }^{3}$ Na obra Pidiendo un Goethe desde dentro (1932), Ortega reivindica conceitos de Heidegger que acredita ter publicado treze anos antes da publicação de O ser e o tempo (1927) (NICOL, 1950, p. 320).

${ }^{4}$ Essa é a primeira defesa escrita da razão histórica como núcleo do seu sistema filosófico (GRACIA, 2014).
} 
pensar a vida humana como movimento progressivo natural e biológico, mas como acontecimento marcado por experiências que anelam presente e passado, indivíduo e sociedade. Assim, o pensamento de Ortega não pode ser comparado ao vitalismo de Nietzsche, pois sua perspectiva não atende à compreensão de um movimento natural progressista que se desenvolve via biologia, muito menos a base da compreensão está centrada na subjetividade do indivíduo por um víeis psicologista, como compreendeu Bergson. Sua ontologia não está fora do sujeito, assim como também a história não é um desenrolar de algo externo que, determinada pela razão, justifica e constitui a realidade do sujeito ao modo hegeliano.

A proposta de Ortega é que, na compreensão da vida humana, a razão exerça sua função de esclarecer de forma contínua as experiências de vida construídas pelos indivíduos através de suas escolhas. "Os temas da vida, da circunstância e da perspectiva estão perfeitamente conectados entre si. Porém os três implicam uma forma de individualismo que postula um novo conceito de razão." (NICOL, 1950, p. 310). Ortega apresenta um método de razão ao qual vai denominar de razão histórica. A primeira vez que Ortega usa essa expressão é em 1910, no texto El hecho de que existan cosas, volume VII, p.206, nova edição. Em 1912, teoriza sobre a ciência histórica no curso Tendencias actuales de la filosofía e, em 1913, com o curso Los problemas de la filosofía de la historia. Porém, desenvolve com maior amplitude e clareza seu pensamento através dos conceitos de razão, história e narrativa em Historia como sistema (1935) e En torno a Galileu (1933), textos correspondentes a seu momento de maturidade intelectual.

Para alguns comentadores, essa é a superação da sua primeira intuição filosófica via razão vital, ao propor como razoável para análise da vida humana um modelo de razão que seja ancorado totalmente na historicidade e voltado para ela enquanto conteúdo da vida humana. Não é uma análise da história no sentido de uma carência factual, mas da vida humana, sendo assim a análise é de cunho ontológico existencial, pois a razão histórica visa analisar o que concretamente é a vida de cada um. Não há como desmembrá-la de uma vida concreta, por isso a narrativa para Ortega aparece como o método mais coerente com a concepção filosófica de vida biográfica por ele apresentada. Os acontecimentos só ganham sentido quando estão sendo analisados diretamente de uma vida concreta e não de uma mera abstração conceitual de um determinado fato, pois "la razón vital [...] para ser auténticamente comprensiva tiene que asumirse como razón histórica." (ARAS, 2008, p. 203).

O conceito de razão histórica tem seus antecedentes teóricos em Dilthey, porém há de se verificar com mais cuidado essa afirmação, porque, antes mesmo de conhecer tal pensador, Ortega já desenvolvera a ideia do eu circunstanciado. Segundo Nicol (1950), Dilthey não foi importante para o filósofo madrilenho somente por influenciá-lo com suas ideias historicistas ou por coincidir com o que ele vinha desenvolvendo pela dimensão histórica da razão vital antes de 1933, mas, muito mais, por reafirmar que seu raciovitalismo desenvolvido desde $E l$ tema de nuestro tiempo (1923) já havia superado o historicismo de Dilthey, mesmo antes de conhecê-lo pela leitura de Introdución a las ciencias del espiritu. A ideia de uma razão histórica e da vida como diálogo com o entorno aparecem como dois grandes pontos em comum entre Ortega e Dilthey, mas Ortega, ao conhecê-lo, já havia superado o historicismo vitalista por um historicismo ontológico. Já 
era claro em seus escritos que a vida humana se constitui pelo que o homem faz da própria vida.

$\mathrm{Na}$ interpretação de Marías, a razão histórica não aparece como outro momento de Ortega, pois compreende que a razão que é vital é histórica, sendo a razão vital "essencialmente histórica" (MARÍAS, 1953, p. 205). A vida aparece como realidade radical, porque funciona como "órgão de compreensão". Entende-se algo na medida em que faz parte da vida (MARÍAS, 1953, p. 207) e, enquanto razão vital, essa vida passa a ser compreendida a partir da existência individual que é pessoal e intransferível. Para Marías (1953, p. 210), somente quando a vida mesma funciona como razão é que conseguimos entender algo humano. A necessidade de uma nova modalidade da razão surge quando a vida passa a ser compreendida como realidade radical.

Na leitura de Bonilla (2013), a filosofia raciovitalista de Ortega está impregnada de razão histórica, porque a vida como tema central de sua obra aparece desde sempre como mudança e, em sua compreensão, essa é a característica central da história. Por isso, é possível falar da historicidade da razão vital e da vitalidade da razão histórica, "porque la vida sólo puede ser comprendida históricamente y la historia sólo puede ser entendida si se analiza desde el punto de vista de la vida humana." (BONILLA, 2013). Nesse sentido, Bonilla parece concordar com a corrente de comentadores orteguianos que defende a razão histórica como uma especificação da razão vital, reafirmando identificar na própria obra de Ortega similaridades entre os dois conceitos de razão. O referido comentador faz a leitura de que a razão vital e a razão histórica se implicam e se complicam, pois, ao mesmo tempo em que Ortega passa a pensar a vida como realidade radical, essa mesma vida tem que ser pensada com base em sua historicidade. Nesse caso, as categorias de vida e de história dialogam pelo conector da existência que é a vida humana.

Em Historia como sistema (1935), Ortega chega a afirmar que a razão vital é também razão histórica, pois a vida que é compreendida só pode ser compreendida em sua dimensão histórica, pois não há nada mais legítimo no homem do que suas experiências de vida e, ao narrá-las, o homem passa a compreender sua vida com base nos acontecimentos que marcam sua existência, tendo como único limite o seu passado. Entender o passado como único limite significa que não há no homem uma natureza determinante, nem uma categoria ontológica absoluta que oriente sua existência, o que o homem tem de concreto é sua vida, que demanda um esforço pessoal para sua realização e compreensão. Assim, o homem é sempre um peregrino, um emigrante ontológico, que carece de uma substancialidade, tendo como conteúdo exclusivo de sua existência a sua história de vida (SEVILLA, 2012, p. 141).

Ao narrar uma vida, o homem não insere nessa narrativa somente elementos individuais, mas também as ideias e crenças que marcam as interferências coletivas na vida individual, porque a história não é um fato isolado, mas um sistema das experiências humanas feitas pelo próprio homem em um movimento dialético com a circunstância que é um horizonte de latência em que as experiências se fazem presentes. Para Ortega, ao compreender a vida na sua dimensão pessoal e intransferível, é preciso pensar conceitos que não sejam os mesmos já pensados pelos gregos de herança eleática como unidade, invariabilidade e permanência, 
pois a vida deve ser pensada por novos conceitos, como experiência de vida, esforço e trasmundo, entre outros (LASAGA, 2015).

O tema da biografia ${ }^{5}$ aparece em Ortega relacionado diretamente à fase histórica da Filosofia da razão vivente, quando, na prática, passa a se interessar por uma escrita que parte de uma compreensão da vida como acontecimento pessoal. Os textos sobre Goethe, Velázquez e Goya manifestam uma forma de pensar que busca compreender como cada indivíduo vai realizando a sua trajetória de vida, indo além de uma simples preocupação em explanar ideias de natureza conceitual, ou de manifestar formas de atuação profissional.

As categorias de vida - existência, sensibilidade e liberdade - são compreendidas na relação com as categorias de geração, idade, tempo, ideias, crenças, revolução, crise e história. Como histórico, o homem é um personagem biográfico, autor de sua própria vida, e um tanto herdeiro da vida social, determinada pelas circunstâncias, não tendo como, na compreensão da vida, desassociar do indivíduo sua dimensão subjetiva e intersubjetiva, pois a vida acontece em primeira pessoa, mas não em um ser único e solitário no mundo. Consideramos trazer uma reflexão relevante para a Filosofia através da temática da vida biográfica, a partir da concepção de razão histórica e narrativa, que, em nossa compreensão aparece como um recurso metodológico e hermenêutico da vida pessoal frente às experiências de vida e do entendimento da relação temporal dos acontecimentos da existência, que sempre acontece em primeira pessoa.

Os grandes temas da história e da vida que irromperam no cenário filosófico com as obras de Nietzsche, Bérgson e Dilthey convenceram Ortega da insuficiência do racionalismo para responder às questões do homem e da história, pois compreendeu ser insustentável pensar à vida a partir de uma razão pura prática. O esforço orteguiano foi superar esse modelo de racionalidade via razão vital. Ortega não só pretende fazer compreensível a história e a realidade humana, mas prioritariamente destacar o papel da razão na compreensão da vida, enaltecendo-a na sua função iluminadora do viver.

A razão em Ortega ocupa o papel de pensar a vida na sua dimensão radical enquanto acontecimento pessoal e intransferível, buscando o sentido dado a cada experiência de vida. A teoria da razão vital é uma análise da vida, das categorias e das dimensões fundamentais do viver que se desenvolve em meio à historicidade e que, embrionariamente, aparece em El tema de nuestro tiempo (1923). Nessa obra, Ortega busca submeter, sem muita originalidade ${ }^{6}$, a razão dentro do desenvolvimento biológico da vida. Compreendê-la implica o reconhecimento do entorno do sujeito que, imbuído em diversos mundos, constitui-se com eles. Superar qualquer forma de redução da vida é o caminho encontrado no segui-

\footnotetext{
${ }^{5}$ Já em 1912, em uma carta a Frederico Onís, Ortega faz referência à biografia no plano pessoal como reconstrução orgânica das variações do sujeito (BONILLA, 2002, p. 166). No entanto, nesse período, Ortega ainda não havia desenvolvido a sua teoria da razão histórica e o tema da biografia aparecia muito mais como referência a um aspecto da história pessoal, pois não tinha a pretensão de apresentá-la como categoria central do seu conceito de vida humana. É em Pidiendo un Goethe desde dentro (1932) que Ortega apresenta claramente o tema da biografia que, diretamente relacionado à sua perspectiva histórica, segue um ciclo comum à vida humana: infância, auge e declínio. Isso para afirmar que existem etapas do pensamento e que ao se deparar com determinados temas, é possível buscar a sua genealogia.

${ }^{6}$ Essa afirmação fundamenta-se no que os críticos falam a respeito do que Ortega escreve na obra, visto que não há nada de novo em sua crítica, pois o texto parece ser carregado do que Nietzsche já fizera ao criticar o primado do racionalismo moderno frente ao esquecimento da dimensão espontânea da vida.
} 
mento do pensamento de Ortega para manter uma coerência com a realidade humana. "El procedimiento de la razón vital ya no será una mera dialéctica conceptual, utópica y ucrónica, sino un acompañamiento de la vida en el que la razón se dirige hacia lo concreto, lo mudable y lo contingente." (ARAS, 2008, p. 201). A razão põe-se a compreender não o que há de fixo e determinado, mas as variações que acontecem na própria vida, pois até mesmo a razão deve ser exercitada, uma vez que faz parte da dimensão da vida e não funciona dela dissociada, como se fosse uma realidade em si mesma, assim como não o é a história, a cultura e, muito menos, o indivíduo existente.

Justifica-se, assim, a vida como objeto fundamental no entendimento da integração indivíduo e realidade. Nas Meditaciones del Quijote (1914), o homem circunstanciado é o primeiro informe de que a razão carece de elementos concretos, pois a salvação da vida passa pelo reconhecimento e pela compreensão do entorno do eu. Casagrande (2002) escreve que a razão pura sufoca a vida, quando não leva em conta o fato de que existe uma conexão ampla entre as coisas, o que não se compreende pelo cálculo puro. Viver é estar situado em uma circunstância e esta carece de sentido. Com a razão vital histórica, Ortega não só pretende fazer compreensíveis a história e a realidade humana, mas, prioritariamente, dar o verdadeiro sentido da razão para a vida, enaltecendo-a em sua função iluminadora do viver.

\section{Referências}

ARAS, R.E. El mito en Ortega. Pamplona: Eunsa, 2008.

BONILLA, J. Z. Ortega y Gasset. Plaza Janes: Barcelona, 2002.

. Ortega y Gasset. Comares: Granada, 2013.

CASAGRANDE, L. Vida e razão: a crítica de Ortega y Gasset à filosofia contemporânea. Caxias do Sul: EDUCS, 2002.

CONILL-SANCHO, J. La superación del naturalismo en Ortega y Gasset. ISEGORÍA, n. 46, enero-junio, 2012.

GARCÍA, A. R. El labirinto de la razón: Ortega y Heidegger. Madrid: Alianza, 1990.

GAOS, J. Sobre Ortega y Gasset y otros trabajos de historia de las ideas en España y la America Española. México: Imprenta universitária, 1957.

GRACIA, J. José Ortega y Gasset. Taurus: Madrid, 2014. (eBook).

MARÍAS, J. Ortega y la idea de la razón vital. Madrid: Antonio Zuñica, 1948. . Introducción a la filosofía. 3. ed. Madrid: Revista del Occidente, 1953.

. Meditaciones del Quijote. (Edición de Julián Marías). 8. ed. Cátedra: Madrid, 2010.

MEDINA, J. L. José Ortega y Gasset (1883-1955): vida y filosofía. Madrid: Biblioteca Nueva, 2003.

NICOL, E. Historicismo y existencialismo: la temporalidade del ser y de la razón. México: El colegio de México, 1950. 
ORTEGA Y GASSET, J. Obras completas. Taurus: Barcelona, 2017. (10 volumes). . Meditación de la técnica. Espase-Calpe: Madrid, 1965. . El tema de nuestro tiempo. Madrid: Revista de Occidente, 2006. . Historia como sistema y otros ensayos de filosofía. Madrid: Revista de Occidente, 2008a. . Espanã invertebrada. Alianza Editorial: Madrid, 2000. . En torno a Galileo. Madrid: Revista de Occidente, 2008b. . Meditaciones del Quijote. Ediciones Catedra: Madrid, 2010a. . El hombre y la gente. Madrid: Revista de Occidente, 2010b. . Qué es filosofía? Madrid: Revista de Occidente, 2010c.

LASAGA, J. La razón histórica como crisis de la razón. Actas: I Congreso Internacional de la Red española de Filosofía, v. XV, p. 31-39, 2015.

KANT, I. La Metafísica de los Costumbres. Trad. Adela Cortina y Jesús Conill Sancho. Madrid: Tecnos,1999.

SEVILLA, J. M. Prolegómenos para una crítica de la razón problemática: motivos en Vico y Ortega. Barcelona: Anthropos, 2011.

\section{Sobre o autor}

\section{Edson Ferreira da Costa}

Doutor em Filosofia pela UFC, professor da UFMA e coordenador do Grupo de Pesquisa Epistemologia e Educação. E-mail: edsonferreiradacosta@gmail.com

Recebido em 16/04/2019

Aprovado em 21/06/2019

\section{Como referenciar esse artigo}

COSTA, Edson Ferreira. A contribuição do pensamento de José Ortega y Gasset sobre o tema da vida na filosofia contemporânea. Argumentos: Revista de Filosofia. Fortaleza, ano 11, n. 22, p. 131-142, jul.-dez. 2019. 